\title{
Clinical Experience with PEGylated Hyaluronic Acid Fillers: A 3-year Retrospective Study
}

\author{
Raffaele Rauso ${ }^{1}$ D, Giovanni Francesco Nicoletti ${ }^{1}$, Pierfrancesco Bove ${ }^{2}$ D, Giuseppe M. Rauso ${ }^{3}$, Romolo Fragola ${ }^{1 *}$ (D), \\ Giorgio Lo Giudice ${ }^{4}$, Nicola Zerbinati ${ }^{5}$ \\ ${ }^{1}$ Department of Surgical, Medical and Dental Specialties, University Hospital "Luigi Vanvitelli", Naples, Italy; ${ }^{2}$ Aesthetic \\ Surgeon Private Practice, Chirurgia della Bellezza, Naples, Italy; ${ }^{3}$ Chief, Centro Polispecialistico Santa Apollonia, Santa \\ Maria Capua Vetere, Italy; ${ }^{4}$ Department of Neurosciences, Reproductive and Odontostomatological Sciences, Maxillofacial \\ Surgery Unit, University of Naples "Federico II", Naples, Italy; ${ }^{5}$ Department of Surgical and Morphological Sciences, University \\ of Insubria, Varese, Italy
}

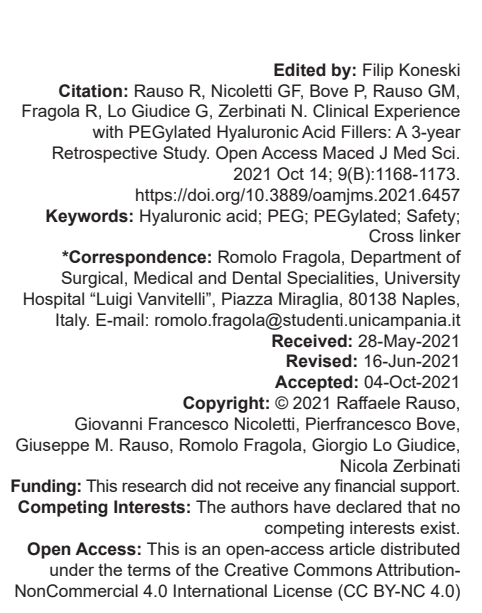

\section{Abstract}

BACKGROUND: Hyaluronic acid fillers are the most used worldwide, thanks to the high biocompatibility and safety profile of HA and it is also the only substance that can be "dissolved" due to the hyaluronidase effect.

AIM: A retrospective clinical evaluation of the outcomes following PEG cross-linked HA-based filler injection was performed.

METHODS: Data were collected from December 2017 to June 2020 . A total of 65 patients (12 M, $53 \mathrm{~F}$ ), age ranging 28-62 year's old (mean age 42.3), were treated. Exclusion criteria were applied and in accord to treatment plan were used specific site injections and fillers. Follow-up was evaluated between 6 months and 2 years.

RESULTS: A total of 61 treatments using 124 vials of HA filler crosslinked with PEG were performed.

CONCLUSION: In conclusion, from 2014, HA fillers having PEG as cross-linker agent have been introduced in the european market Several papers have been published in order to evaluate the features of these fillers, although, to the best of our knowledge, this is the first clinical paper regarding their use.

\section{Introduction}

Hyaluronic acid (HA) fillers are the most used worldwide, this is mainly related to the high biocompatibility and safety profile of HA, moreover, HA is the only substance that can be "dissolved" thanks to the use of hyaluronidase (HYAL) that induce an enzymatic hydrolytic effect [1], [2], [3], [4], [5]. The possibility to hydrolyze $\mathrm{HA}$, once injected, is useful in cases of unpleasant results, however, its main advantage is related to the possibility to treat unwanted side effects such as nodules, and especially vascular problems such as impending necrosis [6], [7]. The first HA-based filler was available in Europe in 1996, however, only in 2003 HA fillers gained also the American FDA approval. HA fillers are characterized by the presence of HA chains linked between each others by a cross-linker agent. The most used cross-linker agent, in order to stabilize HA-based filler, is the 1,4-Butanediol Diglycidyl
Ether known as BDDE: This linking agent reduces the capability of endogenous hyaluronidase to hydrolyze the filler in a short frame of time. Some studies advocate BDDE to have a significantly lower toxicity than other ether-bond cross-linking chemistry based agents (e.g., divinyl sulfone), moreover is biodegradable, and has been well studied. All these factors have contributed to BDDE becoming the industry-standard crosslinker [8]. However, recent studies about tardive inflammatory phenomenon following HA filler injection have pointed out the hypothesis that degradation of cross-linked HA filler may expose trace substances of BDDE that can induce inflammatory phenomenon characterized by tardive swelling or nodule development [9]. In the past years, a new cross-linking agent has been used in order to stabilize HA chains in HA filler industry: The poly (ethylene glycol) also known as PEG. PEG is a biocompatible polymer and has been used for pharmaceutical, cosmetic, and medical applications: It is used for an extremely wide range of products ranging 
from skincare products to tablet formulations, laxatives, and food additives [10], [11]. Furthermore, PEG is FDA approved for several medical applications such as dural repair, vascular repair, pleural air leak repair, wound dressing, and proteins conjugation. Previous histological and in vitro studies have shown a high biocompatibility and safety of HA fillers PEG linked [12], [13], although clinical evidence is lacking. In the present article, authors report their preliminary 3 years of clinical experience with the use of PEGylated HA fillers.

\section{Material and Methods}

A retrospective clinical evaluation of the outcomes following PEG cross-linked HA-based filler injection was performed. Data were collected from December 2017 to June 2020, all the patients were injected by an expert injector (R.R.) and were followed up at least for 6 months; maximum follow up 2 years. A total of 61 patients (12 M, $53 \mathrm{~F}$ ), age ranging 28-62 years old (mean age 42.3), were treated. Exclusion criteria were the following: Patients previously injected with permanent fillers; breastfeeding; pregnancy; any active inflammatory or infectious skin condition at the sites of planned injections; any patient's health condition that could contraindicate the treatment. All the patients were injected at least with $1 \mathrm{~mL}$ of $\mathrm{HA}$ filler cross-linked with PEG (NEAUVIA organic, Matex Lab Spa, Brindisi, Italy); treatments were performed in an office setting, and no premedication or post injective drug therapy was prescribed. Injection points were customized for each patient and a multilayer injection technique, as previously published [14], was performed, using different fillers based on their rheology. Among 65 patients, eight were naive and 57 already experienced HA fillers injections at least 6 months earlier. In accord to the treatment plan, site injections and fillers used were the following:

- $\quad$ Cheekbones; chin; temples, genial angles; radix; anterior nasal spine; anterior maxilla: The injections were performed with a needle inserted almost perpendicular over the periosteum, with a $28 \mathrm{mg} / \mathrm{mL}$ HA filler, G' ranging 420-480 $\mathrm{Pa}$.

- Cheek; mid facial compartments: The injections were performed with a cannula into the superficial and deep subcutaneous fat compartments, with a $22 \mathrm{mg} / \mathrm{mL}$ and $26 \mathrm{mg} / \mathrm{mL}$, respectively, HA filler, G' ranging 270-320 $\mathrm{Pa}$ and 233-276 Pa, respectively.

- Lip: The injections were performed with a needle and were customized per each patient, when a more pronounced lip volume was required (such as the so-called "Russian lips") a $24 \mathrm{mg} / \mathrm{mL}$ filler, G' ranging 320-380, was used. In case a moderate lip volumization was required, the same filler used for mid-facial compartments was preferred.

- $\quad$ Nasal tip and side walls: The injections were performed over the nasal tip dome, the lateral crural, and the upper lateral cartilages with needles, the filler used was the same injected into subcutaneous fat compartments.

- $\quad$ Tear trough: The injections were performed with cannula, over the periosteum, and behind the orbicularis oculi muscle with cannula, the filler used was the same injected into subcutaneous fat compartments.

Filler's features, site injections, injection depths, and technical delivery are summarized in Table 1.

Table 1: Filler's feature, site injections, injection depths and technical delivery

\begin{tabular}{|c|c|c|c|}
\hline $\begin{array}{l}\text { PEGylated filler } \\
\text { features }\end{array}$ & Site injections & Injection depth & Delivery \\
\hline $\begin{array}{l}28 \mathrm{mg} / \mathrm{mL} \mathrm{HA} \mathrm{G}^{\prime} \\
420-480 \mathrm{~Pa}\end{array}$ & $\begin{array}{l}\text { Cheek bones; chin; } \\
\text { temples, genial angles; } \\
\text { radix; anterior nasal } \\
\text { spine; anterior maxilla }\end{array}$ & Over the periosteum & Needle \\
\hline $\begin{array}{l}22 \mathrm{mg} / \mathrm{mL} \mathrm{HA} \mathrm{G} \\
270-320 \mathrm{~Pa}\end{array}$ & $\begin{array}{l}\text { Check; mid facial } \\
\text { compartments } \\
\text { Nasal tip and sidewalls } \\
\text { Lip } \\
\text { Tear Trough }\end{array}$ & $\begin{array}{l}\text { Superficial subcutaneous fat } \\
\text { pads } \\
\text { Over the perichondrium of the } \\
\text { dome, lateal crura and upper } \\
\text { lateral cartilage } \\
\text { Between Orbicularis Oris } \\
\text { Muscle and Mucosa } \\
\text { Over the periosteum and } \\
\text { behind the orbicularis oculii } \\
\text { muscle }\end{array}$ & $\begin{array}{l}\text { Cannula } \\
\text { Needle } \\
\text { Needle } \\
\text { Cannula }\end{array}$ \\
\hline $\begin{array}{l}26 \mathrm{mg} / \mathrm{mL} \text { HA G' } \\
233-276 \mathrm{~Pa}\end{array}$ & $\begin{array}{l}\text { Cheek; mid facial } \\
\text { compartments }\end{array}$ & Dep subcutaneous fat pads & Cannula \\
\hline $\begin{array}{l}24 \mathrm{mg} / \mathrm{mL} \mathrm{G}^{\prime} \\
\text { ranging } 320-380\end{array}$ & Lip & $\begin{array}{l}\text { Between Orbicularis Oris } \\
\text { Muscle and Mucosa }\end{array}$ & Needle \\
\hline
\end{tabular}

Treated areas were the following: 12 lips, six noses, nine tear trough, 14 mid face, eight lower thirds, seven chin, six jaw angle, and three temples. Maximum number of vials used per patient was 6 . At 3 weeks follow-up patients were asked to evaluate their overall satisfaction with a VAS scale with 0 meaning "very dissatisfied" and 10 "really satisfied"; a descriptive statistical analysis was performed. The study followed the principles of the Declaration of Helsinki.

\section{Results}

A total of 61 treatments using 124 vials of HA filler crosslinked with PEG were performed. Ecchymosis, self-resolved within 15 days, was recorded in six cases: Two suborbital and four lips, respectively. In one case, 7 days following the injection, $30 \cup$ of HYAL were administered in order to solve a small lip bump due to an overfilling injection (Figures 1-3); the filler used was the $22 \mathrm{mg} / \mathrm{mL}$ one, with G' ranging 270-320 Pa. No one claimed swelling in the post injective period. The overall patient's satisfaction was evaluated with a VAS scale with 0 as "very dissatisfied" and as 10 "really satisfied". 


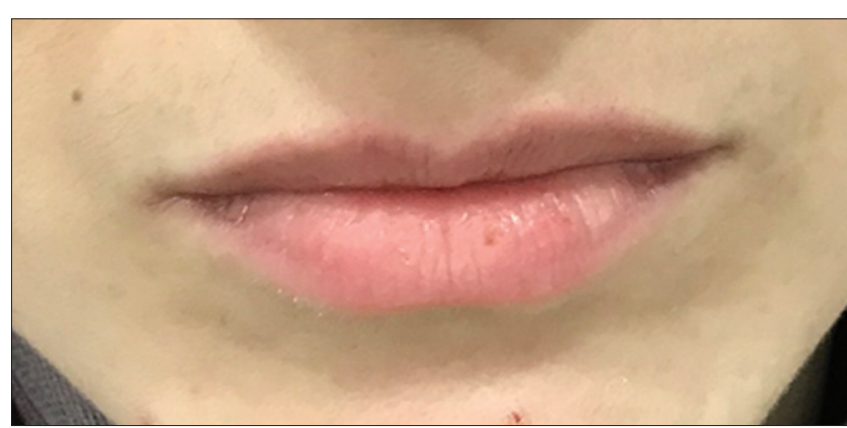

Figure 1: A 32-year-old female asking for lip augmentation. Pre-injection

VAS score, statistically confirmed, was 8.4 on average, ranging from 7 to 10 . Evaluation under 7 was not recorded. No major complications, nor minor such as nodules were recorded.

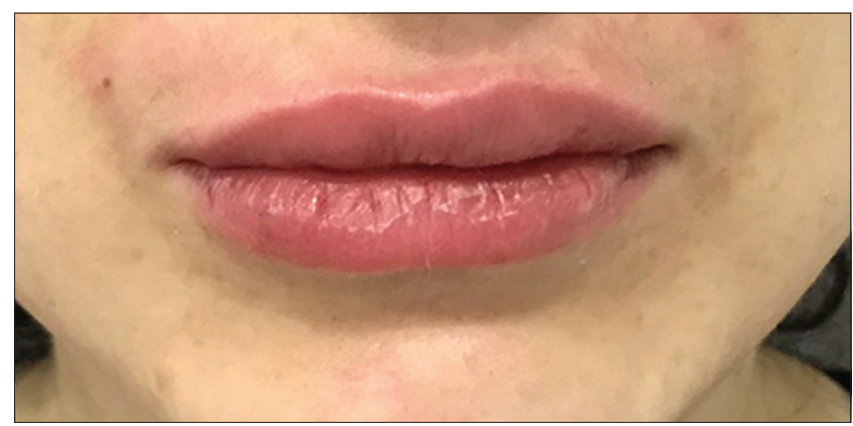

Figure 2: A 32-year-old female asking for lip augmentation. Lip bumps were detected 7 days following HA injections

No nodules or granuloma were recorded during all the follow-up period. The minimum follow-up was 6 months, maximum of 2 years (Figures 4-8).

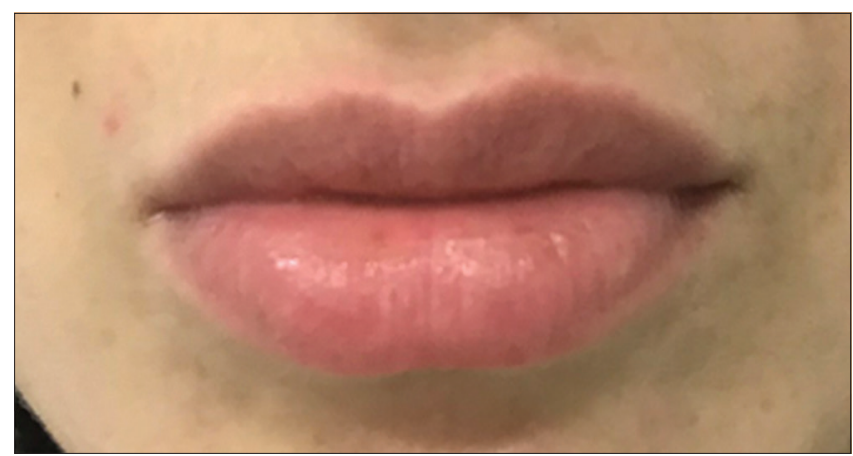

Figure 3: A 32-year-old female asking for lip augmentation. The results were 15 days after the administration of HYAL

\section{Discussion}

Surgical and non-surgical aesthetic procedures performed in the United States, from 1997 to 2016, were recently investigated by ASAPS, the results showed an increase of $+650 \%$ and a $+99 \%$ of non-surgical and surgical procedures, respectively, in this 20 years period [15]. Among non-surgical procedures, botulinum toxin was the most requested [16], although HA fillers were the second.

In 2020, although the COVID-19 pandemic reduced the possibility to get surgical and non-surgical aesthetic procedures, 1,315,378 treatments were carried out with HA fillers in the US [1]. Since its introduction in the market, the use of HA fillers is dramatically changed, moving from the treatments of superficial lines to a total facial aging rehabilitation. Moreover, HA injections, nowadays, are also used for post-surgical corrective procedures, are able to modify muscle contraction (e.g., gummy smile treatment), and so on [17], [18], [19], [20], [21]. HA fillers are the only ones that can be reversed whenever it is needed just injecting HYAL, this confers a really high safety profile to these medical devices and probably this is the reason why, over time, other resorbable substances introduced in the market did not gain the same approval [3], [4]. Since the introduction of HA filler the cross-linking agent main used was represented by BDDE [8]; some attempts to use Divinyl Sulfone (DVS) as cross-linker among HA chains were published, although DVS crosslinker content within the gels in general, stimulate a mild subcutaneous inflammatory response in vivo and VCAM-1 expression by endothelial cells (ECs) cultured atop [22]. BDDE is the cross-linking agent used to stabilize the majority of the HA-based dermal fillers currently available on the market. Its ability to cross-link is attributed to the reactivity of the epoxide groups present at the two ends of the molecule. BDDE has shown a significantly lower toxicity than DVS, is biodegradable, and has been well studied: All these factors have contributed to BDDE becoming the industry-standard cross-linker [8]. On the other hand, some tardive inflammatory phenomenon have been advocated to be related to BDDE concentration, in fact, some studies have tried to show an higher safety and biocompatibility of HA filler with decreased BDDE.
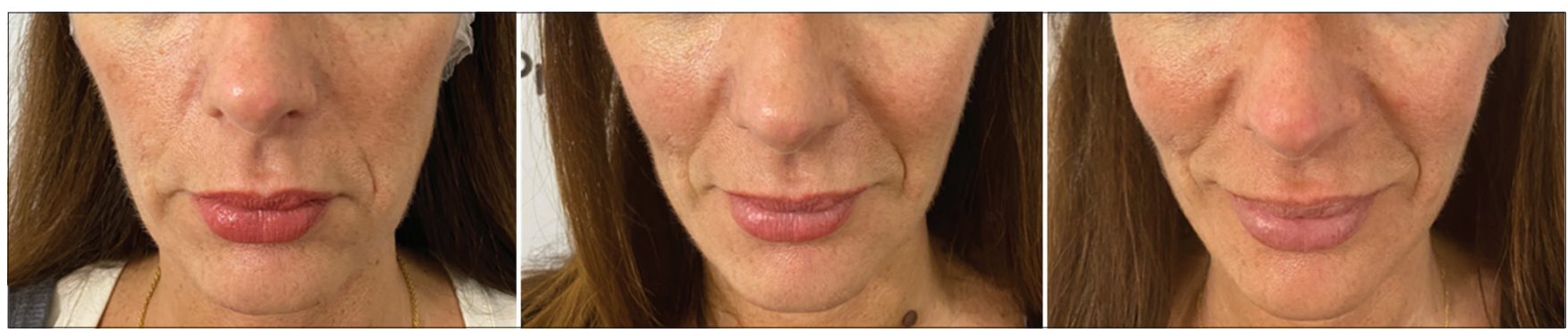

Figure 4: A 45-year-old female mid and lower face contouring fillers. To the left of each pictures the pre-injection appearance, at the center, a 1 month follow-up; to the right the 2 years follow-up; frontal view 

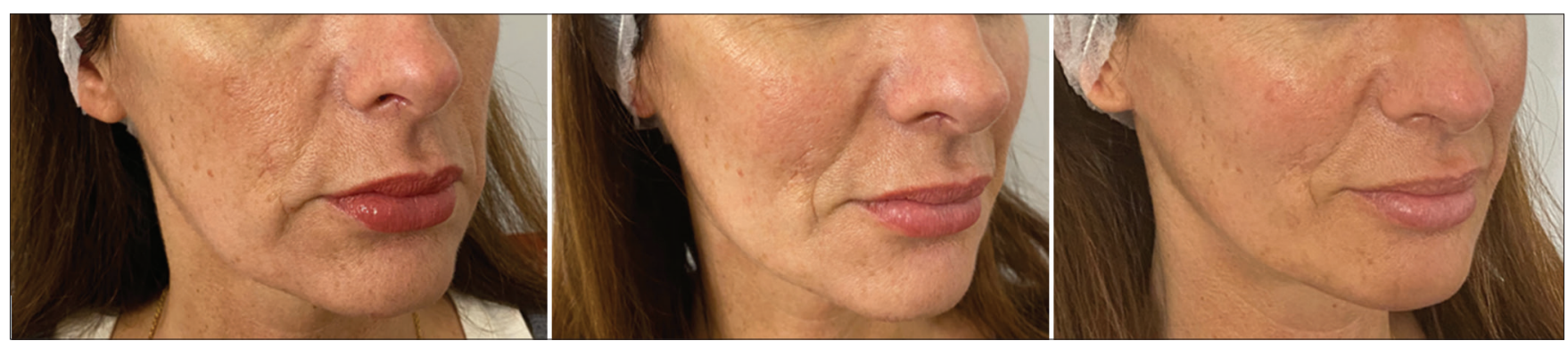

Figure 5: A 45-year-old female mid and lower face contouring fillers. To the left of each pictures the pre-injection appearance, at the center, a 1 month follow-up; to the right the 2 years follow-up; three-quarter right view
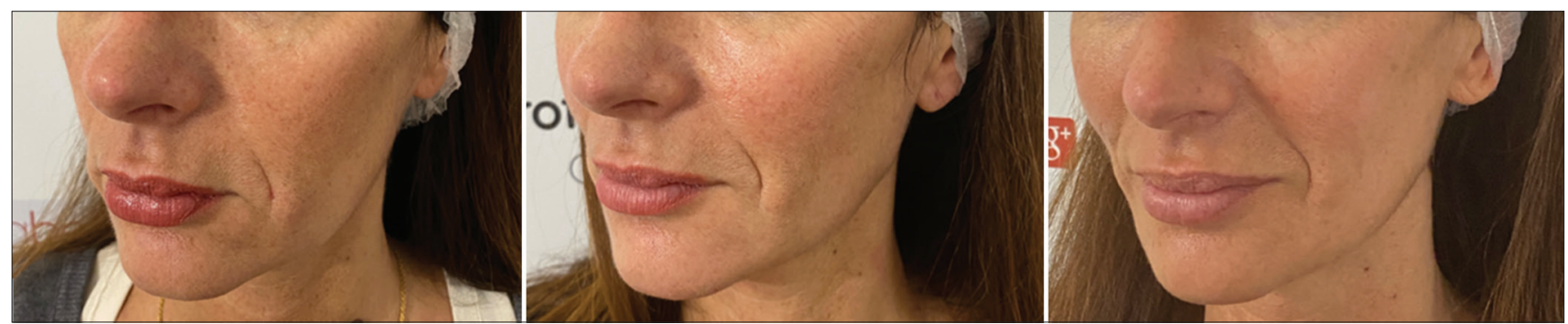

Figure 6: A 45-year-old female mid and lower face contouring fillers. To the left of each pictures the pre-injection appearance, at the center a 1 month follow-up; to the right, the 2 years follow-up; three quarter left view

Moreover, decreased BDDE has been advocate as capable of increase filler elasticity and get more natural results [9]. In 2014, in Europe, for the first time, a HA filler containing PEG as cross-linking agent was introduced in the market. PEG is a polymer and can be used as crosslinking agent in order to obtain the so-called PEGylation process. Furthermore, $\mathrm{HA}$ is a polymer, the cross-linking effect between PEG and HA create a matrices with scaffold structure, a sort of 3D molecular scaffold, that has a better integration with the host tissue, gaining a long-lasting effect and a better resistance to thermal and mechanical stress [23]. The cross-linking between $\mathrm{HA}$ and PEG is characterized by an organic reaction in which an epoxide ring-opening with the hydroxyl group of the $\mathrm{HA}$ and the formation of a $\mathrm{C}-\mathrm{O}-\mathrm{C}$ bond, which is among the most stable bonds and consequently is very resistant to degradation. Several article investigated the features of the PEGylated HA filler used in the present

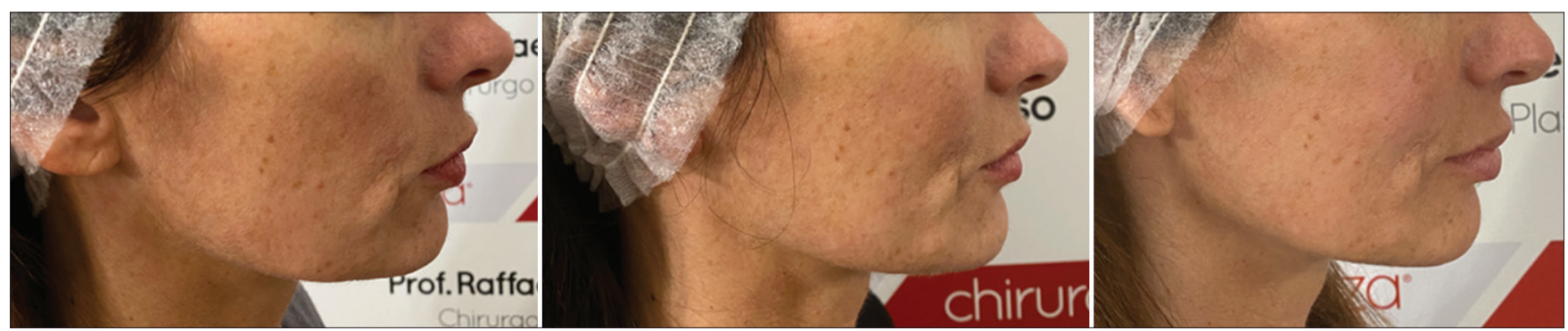

Figure 7: A 45-yearold female mid and lower face contouring fillers. To the left of each pictures the pre-injection appearance, at the center a 1 month follow-up; to the right the 2 years follow-up; lateral right view

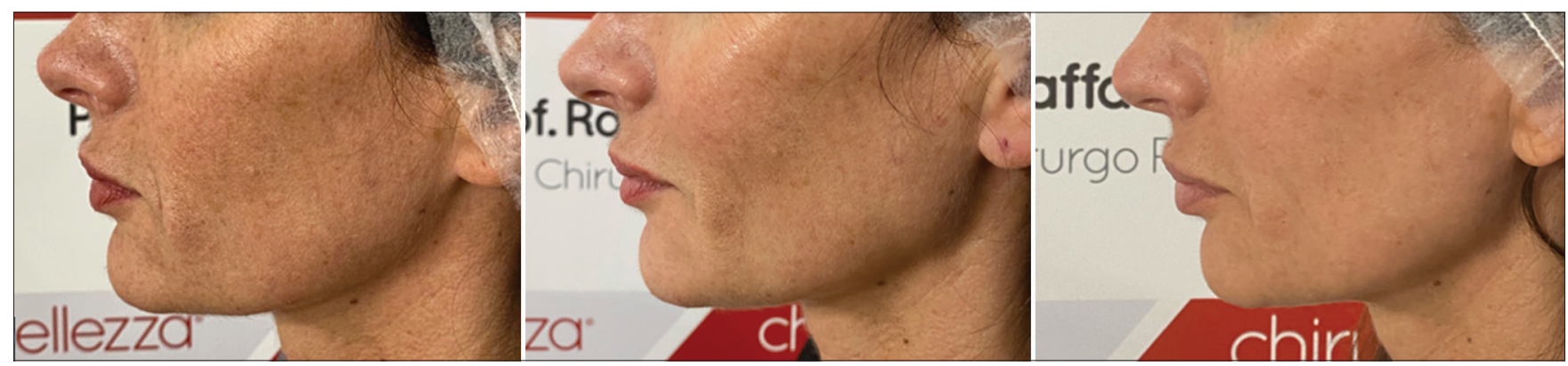

Figure 8: A 45-year-old female mid and lower face contouring fillers. To the left of each pictures the pre-injection appearance, at the center a 1 month follow-up; to the right the 2 years follow-up; lateral left view 
study [10], [11], [12], [13]. Zerbinati et al. evaluated chemical and mechanical characterization of PEGylated HA filler and the result of their study suggested PEGylated HA has a great bio integration, great chemical, and mechanical properties, compared to other products present on the market cross-linked with other agent instead of PEG [12]. Moreover, Zerbinati et al., in another study, analyzed the safety and biocompatibility of PEGylated HA filler: They concluded that safety and biocompatibility properties are related to an $\mathrm{HA}$ produced by genetically modified Bacillus subtilis carrying the gene encoding the enzyme hyaluronic acid synthase (deriving from $S$. equisimilis genome), and further enhanced by the combined use of PEG [24]. Another important issue arisen is related to the long-lasting effect of these fillers: Zerbinati et al. in their study performed several punch biopsies in previously injected areas, 8 months earlier, and noted the filler harmoniously integrated with the structures inside the connective tissue, as collagen fibers, blood, and lymphatic vessels, glands and nerves [11], [25]. The PEGylation process seems to reduce HA sensibility to HYAL [26]. In the present study, we clinically confirmed this issue: We noted a really longlasting result, even when the follow-up was up to 2 years.

Another interesting feature of the PEGylation process is the total absence, up to now, of foreign body reaction or granulomas related to these fillers. Also in the present case series, no side effects related to immunogenicity were detected: As stated by Zerbinati et al., the non-toxicity and non-immunogenicity of PEG guarantee a lack of allergic and immunological reaction [25]. VAS score, reported by treated patients 3 weeks following the injections was 8.4 , but during the 3 weeks post-op consultation it was interesting to hear from the patients their happiness related to the total absence of edema the days following the injections. During the filling injection no over and/or underfilling was performed, the physician injected as much as necessary: At 3 weeks post-injection evaluation no touch-ups were required. On the other hand, in the present study, we noticed a great response of these fillers to HYAL injection: In only one case a lip bump was detected and a complete resolution of the bump was achieved within 10 days from HYAL injection. The present article evaluates retrospectively the clinical experience with PEGylated HA filler, lacking of control group is the main limitation of the present study.

In conclusion, from 2014, HA fillers having PEG as cross-linker agent have been introduced in the european market. Several papers have been published in order to evaluate the features of these fillers, although, to the best of our knowledge, this is the first clinical paper regarding their use.

Clinical outcomes of the present article, showing in a 3-year period no granuloma, foreign body reaction, or other complications, confirm clinically the high safety profile and the high biocompatibility, as already previously shown by histological and in vitro studies released by Zerbinati et al. [25], [26] of PEGylated HA fillers with also long-lasting result.

Randomized controlled clinical trial will be necessary to confirm these statements regarding their clinical use.

\section{Funding}

This research received no external funding.

\section{Institutional Review Board Statement}

Every patient signed an informed consent for the procedures, the use and publication of images and clinical data for scientific research purposes. Data privacy was handled according GDPR.

\section{Informed Consent Statement}

Informed consent was obtained from all subjects involved in the study. Written informed consent was obtained from the patients to publish this paper.

\section{Data Availability Statement}

Data are available from the corresponding author upon request.

\section{References}

1. Available from: https://www.cdn.surgery.org/media/statistics/ aestheticplasticsurgerynationaldatabank-2020stats.pdf. [Last accessed on 2021 Apr 22].

2. Trinh LN, Gupta A. Hyaluronic acid fillers for midface augmentation: A systematic review. Facial Plast Surg. 2021;37(4):536-542. https://doi.org/10.1055/s-0041-1724122 PMid:33634456

3. Rauso R, Sesenna E, Fragola R, Zerbinati N, Nicoletti GF, Tartaro G. Skin necrosis and vision loss or impairment after facial filler injection. J Craniofac Surg. 2020;31(8):2289-93. https://doi.org/10.1097/scs.0000000000007047 PMid:33136873

4. Rauso R, Zerbinati N, Franco R, Chirico F, Ronchi A, 
Sesenna E, et al. Cross-linked hyaluronic acid filler hydrolysis with hyaluronidase: Different settings to reproduce different clinical scenarios. Dermatol Ther. 2020;33(2):e13269. https:// doi.org/10.1111/dth.13269

\section{PMid:32061001}

5. Weiss R, Beer K, Cox SE, Palm M, Kaufman-Janette J, Bassichis B, Biesman B, et al. A Randomized, controlled, evaluator-blinded, multi-center study of hyaluronic acid filler effectiveness and safety in lip fullness augmentation. Dermatol Surg. 2021;47(4):527-32. https://doi.org/10.1097/ dss. 0000000000002856

PMid:33587369

6. Rauso R, Zerbinati N, Fragola R, Nicoletti GF, Tartaro G. Transvascular hydrolysis of hyaluronic acid filler with hyaluronidase:Anexvivostudy. DermatolSurg. 2021;47(3):370-2. https://doi.org/10.1097/dss.0000000000002773 PMid:32932270

7. Rauso R, Colella G, Franco R, Chirico F, Ronchi A, Federico F, Volpicelli A, Tartaro G. Is hyaluronidase able to reverse embolism associated with hyaluronic acid filler? An anatomical case study. J Biol Regul Homeost Agents. 2019;33(6):1927-30. PMid:31960660

8. De Boulle K, Glogau R, Kono T, Nathan M, Tezel A, Roca-Martinez JX, et al. A review of the metabolism of 1 , 4-butanediol diglycidyl ether-crosslinked hyaluronic acid dermal fillers. Dermatol Surg. 2013;39(12):1758-66. https://doi. org/10.1111/dsu.12301

PMid:23941624

9. Rzany B, Converset-Viethel S, Hartmann M, Larrouy JC, Ribé N, Sito $\mathrm{G}$, et al. Efficacy and safety of 3 new resilient hyaluronic acid fillers, crosslinked with decreased BDDE, for the Treatment of dynamic wrinkles: Results of an 18-month, randomized controlled trial versus already available comparators. Dermatol Surg. 2019;45(10):1304-14. https://doi.org/10.1097/ dss.0000000000001971

PMid:31343447

10. Monticelli D, Martina V, Mocchi R, Rauso R, Zerbinati U, Cipolla G, et al. Chemical characterization of hydrogels crosslinked with polyethylene glycol for soft tissue augmentation. Open Access Maced J Med Sci. 2019;7(7):1077-81. https://doi. org/10.3889/oamjms.2019.279

PMid:31049084

11. Zerbinati N, D'Este E, Farina A, Rauso R, Cherubino M, Calligaro A. Morphological evidences following pegylated filler treatment in human skin. J Biol Regul Homeost Agents. 2017;31 Suppl 2:79-85.

12. Zerbinati N, Rauso R, Gonzalez P, Cherubino M, D'Este E, Calligaro $\mathrm{A}$, et al. In vitro evaluation of collagen production on humanfibroblasts treated with hyaluronicacid peg cross-linked with micromolecules of calcium hydroxyapatite in low concentration. J Biol Regul Homeost Agents. 2017;31 Suppl 2:87-90. https:// doi.org/10.3889/oamjms.2018.044

PMid:28702968

13. Zerbinati N, Lotti T, Monticelli D, Rauso R, González-Isaza $P$ D'Este $\mathrm{E}$, et al. In vitro Evaluation of the biosafety of hyaluronic Acid PEG cross-linked with micromolecules of calcium hydroxyapatite in low concentration. Open Access Maced J Med Sci. 2018;6(1):15-9. https://doi.org/10.3889/oamjms.2018.044 PMid:29483971

14. Salti G, Rauso R. Facial rejuvenation with fillers: The dual plane technique. J Cutan Aesthet Surg. 2015;8(3):127-33. https://doi. org/10.4103/0974-2077.167264 PMid:26644734

15. Available from: https://www.surgery.org/sites/default/files/ asaps-stats2016-11-12.pdf. [Last accessed on $2021 \mathrm{Apr} 22]$.

16. Melfa F, Siragusa D, Caruso DG, Tunesi L, Zerbinati N Chirico $\mathrm{F}$, et al. An Italian experience of a new personalized injective protocol (Botutouch) for botulinum toxin application in aesthetic medicine. Dermatol Ther. 2020;33(6):e14395. https:// doi.org/10.1111/dth.14395

PMid:33040423

17. Zerbinati N, Haddad RG, Bader A, Rauso R, D'Este E, Cipolla G et al. A new hyaluronic acid polymer in the augmentation and restoration of labia majora. J Biol Regul Homeost Agents. 2017;31 Suppl 2:153-61.

PMid:28702976

18. Rauso R, Colella G, Zerbinati N, Salti G. Safety and early satisfaction assessment of patients seeking nonsurgical rhinoplasty with filler. J Cutan Aesthet Surg. 2017;10(4):207-14. https://doi.org/10.4103/jcas.jcas_89_17 PMid:29491656

19. Rauso R, Lo Giudice G, Zerbinati N, Tartaro G. Hyaluronic acid injections as nonsurgical alternative in case of delayed diagnosis of malar arch fracture: Case report and literature review. Case Rep Surg. 2019;2019:1360741. https://doi. org/10.1155/2019/1360741

PMid:31976115

20. Rauso R, Tartaro G, Chirico F, Zerbinati N, Albani G, Rugge L. Rhinofilling with hyaluronic acid thought as a cartilage graft. J Craniomaxillofac Surg. 2020;48(3):223-8. https://doi. org/10.1016/j.jcms.2020.01.008

PMid:32107120

21. Rauso R, Federico F, Zerbinati N, de Cicco D, Nicoletti GF, Tartaro G. Hyaluronic acid injections to correct lips deformity following surgical removal of permanent implant. J Craniofac Surg. 2020;31(6):e604-6. https://doi.org/10.1097/ scs.0000000000006689

PMid:32657979

22. Borzacchiello A, Russo L, Malle BM, Schwach-Abdellaoui $\mathrm{K}$, Ambrosio $\mathrm{L}$. Hyaluronic acid based hydrogels for regenerative medicine applications. Biomed Res Int. 2015;2015:871218. https://doi.org/10.1155/2015/871218

PMid:26090451

23. Zerbinati N, Sommatis S, Maccario C, Capillo MC, Grimaldi G, Alonci G, et al. Toward physicochemical and rheological characterization of different injectable hyaluronic acid dermal fillers cross-linked with polyethylene glycol diglycidyl ether. Polymers (Basel). 2021;13(6):948. https://doi.org/10.3390/ polym13060948

PMid:33808730

24. Zerbinati N, Esposito C, Cipolla G, Calligaro A, Monticelli D, Martina $\mathrm{V}$, et al. Chemical and mechanical characterization of hyaluronic acid hydrogel cross-linked with polyethylen glycol and its use in dermatology. Dermatol Ther. 2020;33(4):e13747. https://doi.org/10.1111/dth.13747 PMid:32475040

25. Zerbinati N, Rauso R, Protasoni M, D'Este E, Esposito C, Lotti T, et al. Pegylated hyaluronic acid filler enriched with calcium hydroxyapatite treatment of human skin: Collagen renewal demonstrated through morphometric computerized analysis. J Biol Regul Homeost Agents. 2019;33(6):1967-71. PMid:31920061

26. Zerbinati N, Mocchi R, Galadari H, Maccario C, Maggi M, Rauso $\mathrm{R}$, et al. In vitro evaluation of the biological availability of hyaluronic acid polyethylene glycols-cross-linked hydrogels to bovine testes hyaluronidase. Biomed Res Int. 2019;2019:3196723. https://doi.org/10.1155/2019/3196723

PMid:31309104 